\title{
Interfacial Areas and Gas Hold-ups in Bubble Columns and Packed Bubble Columns at Elevated Pressures
}

\author{
M. H. OYEVAAR*, T. DE LA RIE, C. L. VAN DER SLUIJS and K. R. WESTERTERP** \\ Department of Chemical Engineering, Chemical Reaction Engineering Laboratories, Twente University, \\ PO Box 217, 7500 AE Enschede (The Netherlands)
}

Dedicated to Prof. Dr.-Ing. Dr. h.c./INPL E.U. Schlïnder on the occasion of his 6oth birthday

(Received September 26, 1988; in final form January 13, 1989)

\begin{abstract}
Interfacial areas and gas hold-ups have been determined at pressures up to $1.85 \mathrm{MPa}$ in a bubble column with a diameter of $85.5 \mathrm{~mm}$ and for superficial gas velocities between 1 and $10 \mathrm{~cm} \mathrm{~s}^{-1}$. In some experiments the bubble column was packed with glass cylinders of length $5.0 \mathrm{~mm}$ and diameter $4.0 \mathrm{~mm}$. The interfacial areas were determined by the chemical method using the model reaction between $\mathrm{CO}_{2}$ and aqueous diethanolamine (DEA) and hold-ups by observation of height differences.

The interfacial areas in the packed bubble column are unaffected by pressure. The gas hold-ups as well as the interfacial areas in the bubble column increase with increasing operating pressure. The magnitude of the pressure influence depends on the superficial gas velocity. This positive influence of pressure on the gas hold-ups and the interfacial areas in the bubble column originates from the formation of smaller bubbles at the gas distributor.
\end{abstract}

\section{Introduction}

In this study on mass transfer phenomena in gas-liquid reactors at elevated pressures we present the results of our investigations on interfacial areas and gas hold-ups in a two-phase bubble column operating at pressures up to $1.85 \mathrm{MPa}$. The same experimental procedure as used by Oyevaar et al. [1] for a mechanically agitated gas-liquid reactor is applied to the determination of the mass transfer parameters in the bubble column: the interfacial areas are determined with the chemical method using the reaction between $\mathrm{CO}_{2}$ and aqueous diethanolamine (DEA) and the gas hold-ups by taking the difference in height between the gassed and the nongassed dispersion level respectively. In addition we present some results obtained in a three-phase packed bubble column. This packed bubble column has similar geometry to the packed column used by van Gelder and Westerterp [2] for the determination of the liquid-phase residence time distribution and of hold-ups at elevated pressures.

A considerable amount of information is available on the hydrodynamics and mass transfer characteris-

*Present address: General Electric Plastics bv, Bergen op Zoom, The Netherlands.

**Author to whom correspondence should be addressed. tics in bubble columns. Comprehensive reviews are given by Van Landeghem [3] and Shah et al. [4]. These reviews are restricted to research at atmospheric pressure; nothing is said of a possible influence of the operating pressure on the hydrodynamics and mass transfer parameters in bubble columns, despite the fact that it has been known since the late 1930s that some high pressure bubble columns operate at extremely high gas hold-ups (see refs. 5 and 6).

The upward gas flow in bubble columns is normally characterized by three separate flow regimes, which occur in order of increasing gas flow rate: the bubbly flow, the churn turbulent and the slug flow regime, respectively [4]. In the bubbly flow regime, which occurs at superficial gas velocities below $5 \mathrm{~cm} \mathrm{~s}^{-1}$, the bubble diameters are more or less uniform and the rising velocity of the bubbles lies between 0.18 and $0.30 \mathrm{~m} \mathrm{~s}^{-1}$. At higher superficial gas velocities an unsteady flow pattern occurs and this flow regime, the churn turbulent regime, is characterized by large bubbles moving with high rising velocities in the presence of small bubbles. Increasing the superficial gas velocity further will lead to the formation of very large bubbles stabilized by the reactor walls; this is the slug flow regime.

Earlier [7], we concluded that in pressurized gasliquid systems the initial bubble size at a single orifice decreases with increasing pressure. Several 
authors $[8,9]$ attributed the reduction in size of the bubbles at higher pressures to the increased contribution of the momentum or the kinetic energy to the bubble formation process. Sagert and Quinn [10] observed for some gases an increase in the coalescence time of the gas bubbles when they increased the pressure in their gas-liquid systems. Both phenomena, initially smaller bubbles and larger coalescence times, result in bubbles with lower rising velocities and give rise to larger interfacial areas and gas hold-ups in gas liquid contactors.

Further [1], we found no influence of pressure on the interfacial areas and the gas hold-ups in a mechanically agitated gas-liquid reactor. This may be due to the dominating influence of the agitation or the coalescence-break-up process of the bubbles in this reactor. Such an influence is absent in a bubble column, where the bubble diameters and gas holdups are largely determined by the type of gas distributor and the coalescence-break-up processes in the column. Therefore, if pressure affects the formation of the bubbles or the coalescence-break-up process, an influence of pressure on the interfacial area and the gas hold-up can be expected in a bubble column.

All literature data on mass transfer parameters in bubble columns at elevated pressures are summarized in Table 4 of Oyevaar and Westerterp [7]. In Fig. 7 of that study it has been shown that a twofold increase in the gas hold-up with a pressure increase from 0.1 to $2.0 \mathrm{MPa}$ can be oblained. However, studies in bubble columns are also known in which no influence of pressure on the gas hold-up and the bubble diameters has been found. A remarkable point is that all the studies which report no influence of pressure were executed in bubble columns with porous plates as gas distributors and with low superficial gas velocities between 0.1 and $3.5 \mathrm{~cm} \mathrm{~s}^{-1}$.

Idogawa et al. [11] reported that with increasing pressure at a single orifice the critical gas velocity separating the multiple bubbling and jetting regions decreases. Such a change was also observed for the flow regimes in a bubble column by Tarmy et al. [5,6] and Teurlings et al. [12]. These authors reported that at higher pressures the transition from bubbly flow towards the churn turbulent regime occurs at higher gas velocities and higher gas holdups. Tarmy et al. $[5,6]$ remarked that the persistence of the bubbly flow regime at higher gas hold-ups can be caused by the presence of very small non-coalescing bubbles at higher pressures. This combination of larger gas hold-ups and smaller bubble diameters may lead to considerably larger interfacial areas at elevated pressures.

Only Idogawa et al. [13] determined gas hold-ups and bubble diameters simultaneously in a bubble column at elevated pressures. For air-water at a constant superficial gas velocity of $1 \mathrm{~cm} \mathrm{~s}^{-1}$ their correlations predict an increase in the gas hold-up by a factor of 2.7 and a decrease in the average bubble diameter by a factor of 0.6 , when the pressure is increased from 0.1 up to $5 \mathrm{MPa}$ : this results in an increase by a factor of 4.5 in the interfacial area.
Such an extremely large influence of the operating pressure on the interfacial area should be a strong incentive for further research into this phenomenon in bubble columns.

\section{Experimental}

\subsection{Experimental method}

The interfacial areas are determined by the chemical method using the model reaction between $\mathrm{CO}_{2}$ and aqueous diethanolamine (DEA). We showed [1] that the absorption rate, as derived by Danckwerts [14] for the penetration theory, becomes equal to

$$
\begin{aligned}
\phi_{\mathrm{CO}_{2}} & =m k_{\mathrm{L}} a V_{\mathrm{R}} E_{\mathrm{A}} \Delta c_{\mathrm{CO}_{2}, \mathrm{G}} \\
& =m k_{\mathrm{L}} a V_{\mathrm{R}}\left(1+\mathrm{Ha}^{2}\right)^{0.5} \Delta c_{\mathrm{CO}_{2}, \mathrm{G}}
\end{aligned}
$$

If the conditions for the pseudo-first-order reaction regime,

$2<\mathrm{Ha} \ll E_{\mathrm{A}, \infty}$

with

$\mathrm{Ha}=\left[k_{1, p}\left(c_{\mathrm{DEA}, \mathrm{L}}\right)^{p} D_{\mathrm{CO}_{2}}\right]^{0.5} / k_{\mathrm{L}}$

and

$E_{\mathrm{A}, \infty}=\left(\frac{D_{\mathrm{CO}_{2}}}{D_{\mathrm{DEA}}}\right)^{0.5}+\left(\frac{D_{\mathrm{DEA}}}{D_{\mathrm{CO}_{2}}}\right)^{0.5} \frac{c_{\mathrm{DEA}, \mathrm{L}}}{m c_{\mathrm{CO}_{2}, \mathrm{G}} v_{\mathrm{B}}}$

are met, the interfacial areas can be obtained from absorption rate measurements without knowledge of the exact value of the liquid-phase mass transfer coefficient $k_{\mathrm{L}}$.

The gas phase in the bubble column reactor can be assumed to be in plug flow and for this case the average driving force for mass transfer, $\Delta c_{\mathrm{CO}_{2}, \mathrm{G}}$, becomes equal to

$\Delta c_{\mathrm{CO}_{2}, \mathrm{G}}=\frac{c_{\mathrm{CO}_{2}, \mathrm{G}, \text { in }}-c_{\mathrm{CO}_{2}, \mathrm{G}, \text { out }}}{\ln \left(c_{\mathrm{CO}_{2}, \mathrm{G}, \text { in }} / c_{\mathrm{CO}_{2}, \mathrm{G}, \text { out }}\right)}$

This results in the following equation from which the interfacial areas in the bubble column can be calculated:

$a=\frac{\phi_{\mathrm{V}} \ln \left(c_{\mathrm{CO}_{2}, \mathrm{G}, \text { in }} / c_{\mathrm{CO}_{2, \mathrm{G}, \text { out }}}\right)}{m V_{\mathrm{R}}\left[k_{1, p}\left(c_{\mathrm{DEA}, \mathrm{L}}\right)^{p} D_{\mathrm{CO}_{2}}\right]^{0.5}}$

The same commercial grade aqueous DEA solutions as used by Oyevaar et al. [1] are used for the determination of the interfacial areas in the bubble column. An empirical correlation for the absorption rate constant $m\left[k_{1, p}\left(c_{\mathrm{DEA}, \mathrm{L}}\right)^{p} D_{\mathrm{CO}_{2}}\right]^{0.5}$ at $298 \mathrm{~K}$ in the gas-liquid reaction system as a function of the free DEA concentration $\left(0.2-2.0 \mathrm{~mol} \mathrm{~kg}^{-1}\right)$ is given in eqn. (7) in Table 1. Experimentally determined correlations for the solubility $m$, the viscosity $\mu_{\mathrm{L}}$ and the density $\rho_{\mathrm{L}}$ as a function of the total DEA concentration are also given in eqns. (8), (9) and (10) in the same Table.

For each absorption experiment the $\mathrm{CO}_{2}$ concentrations in the inlet and outlet gas flows, the DEA concentration and the $\mathrm{CO}_{2}$-liquid load in the inlet 
TABLE 1. Data for the DEA-water system at $298 \mathrm{~K}$

$$
\begin{aligned}
m\left[k_{1, p}\left(c_{\mathrm{DEA}, \mathrm{L}}\right)^{p} D_{\mathrm{CO}_{2}}\right]^{0.5}= & 9.39 \times 10^{-4}[\mathrm{DEA}]_{\mathrm{free}}{ }^{0.38} \\
& -2.61 \times 10^{-4} \mathrm{~m} \mathrm{~s}^{-1} \\
m= & 0.791-0.044[\mathrm{DEA}]^{*} \\
\rho_{\mathrm{L}}= & 995.8+15.55[\mathrm{DEA}]-1.141[\mathrm{DEA}]^{2} \mathrm{~kg} \mathrm{~m}^{-3} \\
\mu_{\mathrm{L}}= & 10^{-3} \exp (-0.1135+0.257[\mathrm{DEA}] \\
& \left.+4.694 \times 10^{-2}[\mathrm{DEA}]^{2}\right) \quad \mathrm{N} \mathrm{s} \mathrm{m}^{-2}
\end{aligned}
$$

[DEA] in $\mathrm{mol} \mathrm{kg}^{-1}$ and $[\mathrm{DEA}]^{*}$ in $\mathrm{mol}^{-1}$.

liquid flow are determined separately. The tutal DEA concentration is corrected for the $\mathrm{CO}_{2}$-liquid load in the feed and for the amount of $\mathrm{CO}_{2}$ absorbed from the gas phase, as part of the DEA in the feed and in the reaction mixture itself is already converted. The resulting free DEA concentration is used for the calculation of the absorption rate constant from eqn. (7) and then for each absorption experiment the interfacial areas are calculated from eqn. (6).

\subsection{Experimental installation and procedure}

The same experimental installation as described in detail in ref. 1 is used for the absorption experiments in the bubble column reactors. Only the mechani- cally agitated reactor is replaced by a column, also made of glass, manufactured by SFS (Zurich) (see Fig. 1). It has a diameter $D=85.5 \mathrm{~mm}$ and a total height of $63.0 \mathrm{~cm}$. The column can be operated at pressures up to $2.0 \mathrm{MPa}$ and is thermostatted at a constant temperature of $298 \mathrm{~K}$. The column is operated continuously with respect to both the gas and the liquid phase. A gas mixture of $\mathrm{CO}_{2}$ and $\mathrm{N}_{2}$ is introduced into the column via a gas distributor located at the bottom. A liquid inlet tube is installed at the top of the column just below the dispersion level, resulting in a countercurrent flow of gas and liquid through the column. The dispersion level is kept at a constant height of $H / D=6.1$. In order to obtain a uniform bubble flow through the bubble column, in most of the experiments we used a crossshaped gas distributor with 16 holes of diameter $0.5 \mathrm{~mm}$ (Fig. 1).

For the experiments with a packed bubble column we filled the column with glass cylinders of length $5.0 \mathrm{~mm}$ and diameter $4.0 \mathrm{~mm}$. The density of the packing material is equal to $2200 \mathrm{~kg} \mathrm{~m}^{-3}$ column and the bed porosity 0.35 . The packed column also operates continuously with respect to both the gas and liquid phase and the phases flow countercurrently. The cross-shaped gas distributor in the packed bubble column leads to serious maldistributions of the gas. Therefore, we replaced it by a circular
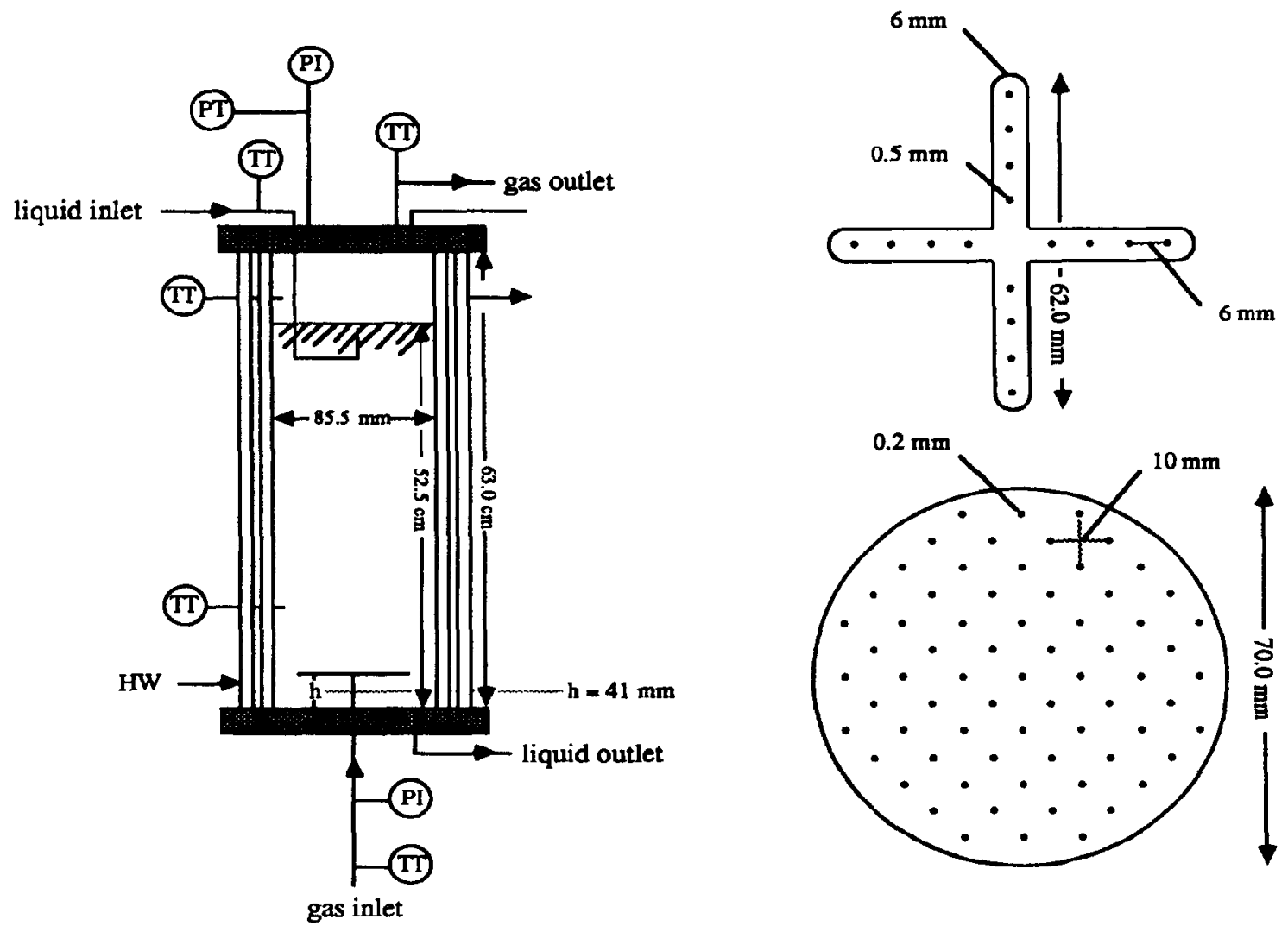

Fig. 1. The experimental bubble column reactor with the two gas distributors. 
distributor with 69 holes of diameter $0.2 \mathrm{~mm}$ for the experiments with the packed bubble column (Fig. 1).

The same experimental procedure as described previously [1] is followed for all the absorption measurements. Special care is taken to keep the DEA conversion below $20 \%$. The gas hold-ups are determined by measuring the height difference between the gassed and non-gassed dispersion level. As the gas distributors are $41 \mathrm{~mm}$ high we subtracted $41 \mathrm{~mm}$ from the dispersion height. So all the reported specific interfacial areas and gas hold-ups are based on the true reaction volume above the gas distributor.

\subsection{Liquid-phase mass transfer coefficients and experimental conditions}

As stated before, we do not need to know the exact value of $k_{\mathrm{L}}$ for the determination of the interfacial area if the conditions of eqn. (2) for the pseudo-first-order reaction regime are fulfilled. However, a rough idea of the magnitude of $k_{L}$ and its dependence on the operating conditions is necessary in order to know whether $\mathrm{Ha}$ is larger than 2. This allows us to estimate the DEA concentrations in the liquid phase and $\mathrm{CO}_{2}$ concentrations in the gas phase at which the conditions of eqn. (2) are met, so that the interfacial areas can be determined. Previously [7], it was concluded that the liquid-phase mass transfer coefficient in gas-liquid reactors is not affected by the operating pressure. Therefore, $k_{\mathrm{L}}$ can be determined under atmospheric conditions and the results can be used for the choice of the experimental conditions at elevated pressures.

By means of the Danckwerts plot method we determined $k_{\mathrm{L}}$ in a series of absorption experiments at one constant pressure, $P=0.15 \mathrm{MPa}$, and at four different superficial gas velocities, $v_{\mathrm{G}}=1.0,2.0,4.0$ and $6.0 \mathrm{~cm} \mathrm{~s}^{-1}$. This method is based on a form of eqn. (1), rewritten as

$$
\left(\frac{\phi_{\mathrm{CO}_{2}}}{V_{\mathrm{R}} m \Delta c_{\mathrm{CO}_{2}, \mathrm{G}}}\right)^{2}=\left(k_{\mathrm{L}} a\right)^{2}+a^{2} k_{1, p}\left(c_{\mathrm{DEA}, \mathrm{L}}\right)^{p} D_{\mathrm{CO}_{2}}
$$

By plotting the left-hand side of eqn. (11) against $k_{1, p}\left(c_{\mathrm{DEA}, \mathrm{L}}\right)^{p} D_{\mathrm{CO}_{2}}$ the values for $k_{\mathrm{L}}$ and $a$ can be obtained by combination of the slope and the intercept on the vertical axis of the straight line through the experimental results.

The absorption experiments were performed in six different aqueous DEA solutions with DEA concentrations between 0.10 and $1.10 \mathrm{~mol} \mathrm{~kg}{ }^{-1}$. This results in a fortyfold variation in $k_{1, p}\left(c_{\mathrm{DEA}, \mathrm{L})}{ }^{p} D_{\mathrm{CO}_{2}}\right.$. The Danckwerts plots obtained from these experiments are shown in Fig. 2. A major drawback of this method is the variation in the liquid-phase properties of the different solutions, which may affect the hydrodynamics in the reactor. This may give rise to experimental errors, especially in $\mathrm{CO}_{2}$-amine systems in which the variation in the reaction rate can only be realized by changing the amine concentrations and not by the addition of a catalyst. However, the

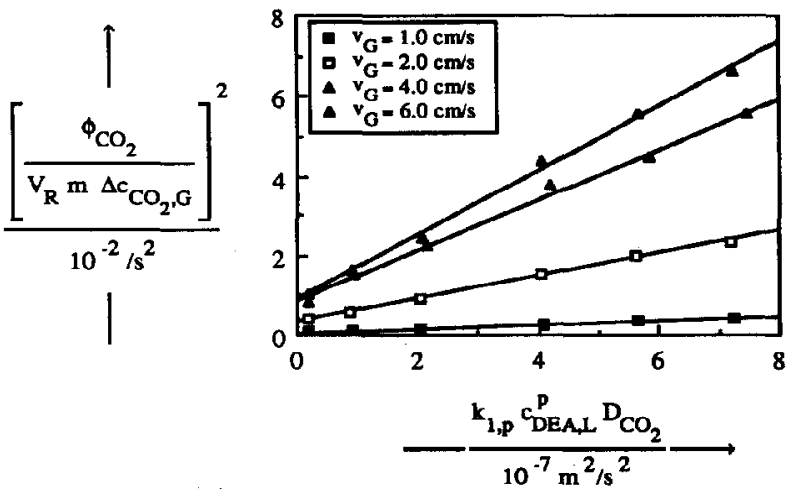

Fig. 2. Danckwerts plots for the bubble column at a pressure of $0.15 \mathrm{MPa}$.

tenfold change in the DEA concentration from 0.10 to $1.10 \mathrm{~mol} \mathrm{~kg}^{-1}$ causes only a minor change in the liquid-phase viscosity from $0.92 \times 10^{-3}$ to $1.25 \times 10^{-3} \mathrm{~N} \mathrm{~s} \mathrm{~m}^{-2}$ and can probably be neglected. This is confirmed by the Danckwerts plots in Fig. 2, which exhibit straight lines over the whole range of operating conditions and indicate that $k_{\mathrm{L}}$ and $a$ are constant within the applied range of viscosities.

The values of $k_{\mathrm{L}}$ and $a$ which are obtained from Fig. 2 are summarized in Table 2 . It can be seen that $k_{\mathrm{L}}$ is practically constant over the range of superficial gas velocities applied: it has an average value equal to $3.5 \times 10^{-4} \mathrm{~m} \mathrm{~s}^{-1}$. The same independence of the liquid-phase mass transfer coefficient has been reported recently by Schumpe et al. [15]. These authors have calculated values for $k_{\mathrm{t}}$ from individual results on $a$ and $k_{\mathrm{L}} a$, obtained in a bubble column with a diameter $D=9.1 \mathrm{~cm}$ with the gas-liquid system $\mathrm{O}_{2}$-aqueous sodium sulphite $\left(0.8 \mathrm{~N} \mathrm{Na}_{2} \mathrm{SO}_{3}\right)$. They found a constant $k_{\mathrm{L}}$-value of about $3.2 \times 10^{-4} \mathrm{~m} \mathrm{~s}^{-1}$, which agrees rather well with the average $k_{\mathrm{L}}$ from this study.

The interfacial areas increase with an increasing superficial gas velocity up to $4 \mathrm{~cm} \mathrm{~s}^{-1}$, but above that start to decrease. The decrease in the interfacial area indicates a transition from bubbly flow to the churn turbulent flow regime around $v_{G}=5 \mathrm{~cm} \mathrm{~s}^{-1}$, which is likely to occur around this superficial gas velocity according to Shah et al. [4]. A decrease in the interfacial area after the transition from one flow regime to another has already been reported by Schumpe and Deckwer [16] and will also be discussed further on in this study.

TABLE 2. Results of the Danckwerts plots for the bubble column at a pressure of $0.15 \mathrm{MPa}\left([\mathrm{DEA}]=0.10-1.10 \mathrm{~mol} \mathrm{~kg}{ }^{-1}\right.$ )

\begin{tabular}{lll}
\hline $\begin{array}{l}v_{\mathrm{G}} \times 10^{2} \\
\left(\mathrm{~m} \mathrm{~s}^{-1}\right)\end{array}$ & $\begin{array}{l}k_{\mathrm{L}} \times 10^{4} \\
\left(\mathrm{~m} \mathrm{~s}^{-1}\right)\end{array}$ & $\begin{array}{l}a \\
\left(\mathrm{~m}^{-1}\right)\end{array}$ \\
\hline 1.0 & 3.54 & 71 \\
2.0 & 3.38 & 170 \\
4.0 & 3.39 & 283 \\
6.0 & 3.78 & 251 \\
\hline
\end{tabular}




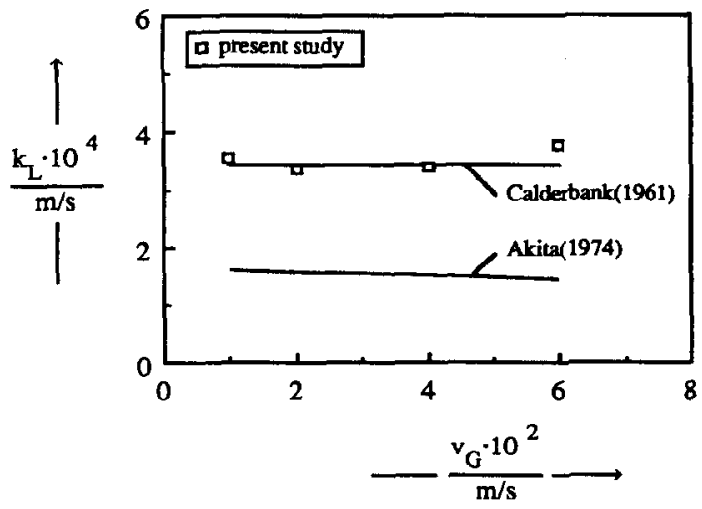

Fig. 3. Comparison between literature correlations for $k_{\mathrm{L}}$ by Calderbank and Moo-Young [17] and Akita and Yoshida [18] and data from the present study.

A comparison with literature correlations, as given for the liquid-phase mass transfer coefficients in bubble columns by Calderbank and Moo-Young [17] and Akita and Yoshida [18], is made in Fig. 3. The data for $k_{\mathrm{L}}$ from the present work coincide with the relation of Calderbank and Moo-Young [17] and differ by a factor of 2.5 from the relation of Akita and Yoshida [18]. Therefore, it can be concluded that the use of an average value of $k_{\mathrm{L}}=3.5 \times 10^{-4} \mathrm{~m} \mathrm{~s}^{-1}$ leads to conservative values of the DEA concentration at which the condition $\mathrm{Ha}>2$ in eqn. (2) is fulfilled.

From eqns. (7) and (8) it can be calculated that with $k_{\mathrm{L}}=3.5 \times 10^{-4} \mathrm{~m} \mathrm{~s}^{-1}$ the free DEA concentration should be equal to $1.6 \mathrm{~mol} \mathrm{~kg}^{-1}$ to obtain a Hatta number of 3.5. Together with the experimental condition of a maximum DEA conversion of $20 \%$ this leads to a minimum value for the total DEA concentration of $2.0 \mathrm{~mol} \mathrm{~kg}^{-1}$ for the amine solutions with which the interfacial areas in the bubble column can be determined. All interfacial areas for the bubble column will be determined with amine solutions with a total DEA concentration between 2.0 and $2.2 \mathrm{~mol} \mathrm{~kg}^{-1}$. The $\mathrm{CO}_{2}$ fractions supplied in the gas feed are the same as in the mechanically agitated reactor and range from $1 \%$ to $2 \%$. For values of $D_{\mathrm{DEA}} / D_{\mathrm{CO}_{2}}=0.5$ and $m=0.7-0.8$ at a temperature of $298 \mathrm{~K}$ this results, at all pressures, in values of $E_{\mathrm{A}, \infty}>60$.

\section{Results}

\subsection{Gas hold-ups in the bubble column}

\subsubsection{Experimental results}

Gas hold-up measurements were performed with nitrogen in distilled water and in an aqueous DEA solution partially loaded with $\mathrm{CO}_{2}$ having $c_{\mathrm{DEA}, \mathrm{L}}=$ $2.16 \mathrm{~mol} \mathrm{~kg}^{-1}$ and $c_{\mathrm{CO}_{2 .} \mathrm{L}}=0.190 \mathrm{~mol} \mathrm{~kg}^{-1}$. The results are plotted in Figs. 4 and 5. The operating pressures of these measurements range from 0.15 to

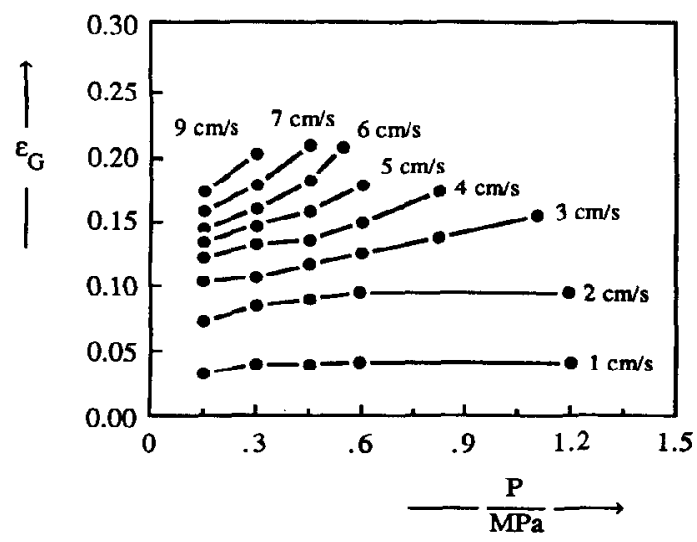

Fig. 4. Gas hold-ups in water vs. the reactor pressure in the bubble column.

$1.85 \mathrm{MPa}$ and the superficial gas velocities vary between 1.0 and $9.0 \mathrm{~cm}^{-1} \mathrm{~s}$. Because of experimental restrictions it is not possible to work below pressures of $0.15 \mathrm{MPa}$ and to use gas flows larger than $2.0 \times 10^{-3} \mathrm{~m}^{3} \mathrm{~s}^{-1}$. The gas hold-ups cannot be determined with sufficient accuracy at gas velocities above $10 \mathrm{~cm} \mathrm{~s}^{-1}$ and the reported results are therefore also restricted to gas velocities below $10 \mathrm{~cm} \mathrm{~s}^{-1}$.

It is evident from Figs. 4 and 5 that the operating pressure has a positive influence on the gas hold-up. Both Figures show an increase in the gas hold-up with increasing pressure. It can be seen that both the relative and the absolute increase in the gas hold-up are larger in the aqueous DEA solution than in water. For water the relative increase of the gas hold-up can be calculated to be independent of the applied superficial gas velocity; for a pressure increase from 0.15 to $0.30 \mathrm{MPa}$ it amounts to $10 \%$ $20 \%$ and for an increase from 0.15 to $0.60 \mathrm{MPa}$ it amounts, at all gas velocities, to $20 \%-30 \%$. In contrast, for the aqueous DEA solution the relative increase of the gas hold-up depends on the gas velocities; for a pressure increase from 0.15 to $0.30 \mathrm{MPa}$ it ranges from $20 \%$ at low superficial gas

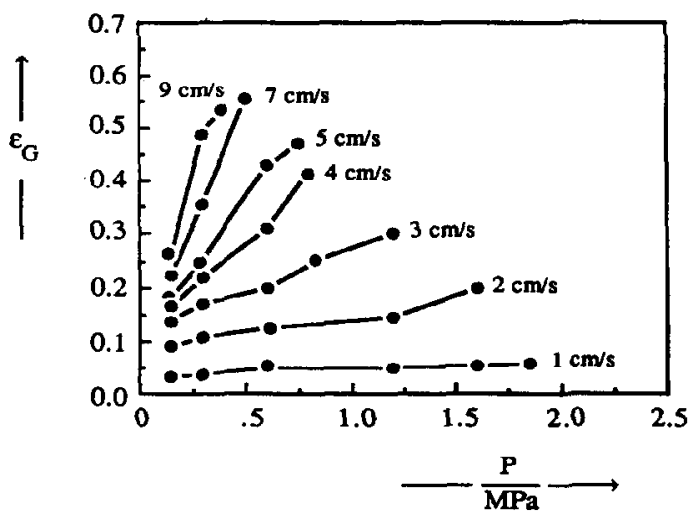

Fig. 5. Gas hold-ups in a DEA solution partially loaded with $\mathrm{CO}_{2}$ vs. the reactor pressure in the bubble column. 
velocities to $90 \%$ at high superficial gas velocities. Comparison of the gas hold-ups in the aqueous DEA solution at 0.15 and $0.60 \mathrm{MPa}$ shows a relative increase of the gas hold-up ranging from $40 \%$ to $150 \%$.

\subsubsection{Comparison with literature correlations}

The correlations of Akita and Yoshida [19] and Hikita et al. [20] are recommended by Shah et al. [4] for the calculation of gas hold-ups in bubble columns with single or multi-nozzle gas distributors. These correlations (given in Table 3) are based on atmospheric measurements. Hikita et al. [20] used different gases with different densities to account for the effect of the gas density on the gas hold-up. It has been argued by Pijls et al. [21] that the effect of the operating pressure on the gas holdup cannot be simulated by using gases of different densities. Also, our results show a much larger dependence on the gas density than suggested by the exponent 0.062 in the relation of Hikita et al. [20].

A comparison between the gas hold-ups at $0.15 \mathrm{MPa}$ from this study and the relations in Table 3 is given in Fig. 6. It can be seen that the gas hold-ups in water agree fairly well with the correlations, whereas those in the aqueous DEA solution differ substantially compared to the gas hold-ups predicted by Akita and Yoshida [19] and Hikita $e t$ al. [20]. Recently, Öztürk et al. [22] also reported gas hold-ups in mixtures of liquids to be sometimes higher than those calculated from the aforementioned literature correlations, which have been derived on the basis of measurements in water and in pure organic liquids.

A comparison between our experimental gas holdups in water and those predicted by the correlation for gas hold-ups in a bubble column at elevated

TABLE 3. Literature correlations on the gas hold-up and the interfacial areas in bubble columns

$$
\begin{aligned}
& \frac{\varepsilon_{\mathrm{G}}}{\left(1-\varepsilon_{\mathrm{G}}\right)^{4}}=0.20\left(\frac{g D^{2} \rho_{\mathrm{L}}}{\sigma_{\mathrm{L}}}\right)^{0.125} \\
& \times\left(\frac{g D^{3}}{v_{L}^{2}}\right)^{0.083} \frac{v_{G}}{(g D)^{0.5}} \\
& a D=\frac{1}{3}\left(\frac{g D^{2} \rho_{\mathrm{L}}}{\sigma_{\mathrm{L}}}\right)^{0.50}\left(\frac{g D^{3}}{v_{\mathrm{L}}{ }^{2}}\right)^{0.10} \varepsilon_{\mathrm{G}}{ }^{1.13} \quad \text { Akita and Yoshida [18] } \\
& \varepsilon_{\mathrm{G}}=0.672 f\left(\frac{v_{\mathrm{G}} \mu_{\mathrm{L}}}{\sigma_{\mathrm{L}}}\right)^{0.578}\left(\frac{\mu_{\mathrm{L}}^{4} g}{\rho_{\mathrm{L}} \sigma_{\mathrm{L}}^{3}}\right)^{-0.131} \\
& \times\left(\frac{\rho_{\mathrm{G}}}{\rho_{\mathrm{L}}}\right)^{0.062}\left(\frac{\mu_{\mathrm{G}}}{\mu_{\mathrm{L}}}\right)^{0.107}
\end{aligned}
$$

Akita and Yoshida investigated column diameters in the range $0.15-0.6 \mathrm{~m}$.

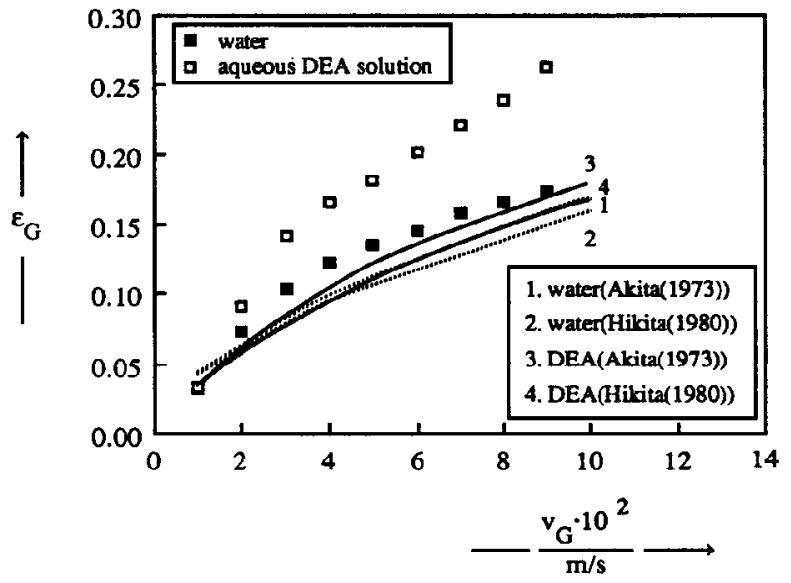

Fig. 6. Comparison between literature correlations for $\varepsilon_{\mathrm{G}}$ and the data of the present study at $P=0.15 \mathrm{MPa}$ (Akita (1973) $=$ ref. 19; Hikita $(1980)=$ ref. 20).

pressures, as presented by Idogawa et al. [13],

$\frac{\varepsilon_{\mathrm{G}}}{1-\varepsilon_{\mathrm{G}}}=1.44 v_{\mathrm{G}}{ }^{0.58} \rho_{\mathrm{G}}{ }^{0.12} \sigma_{\mathrm{L}}{ }^{-0.16 \exp (-P)}$

(in SI units, except for $P$ in $\mathrm{MPa}$ and $\sigma_{\mathrm{L}}$ in $\mathrm{mN} \mathrm{m}^{-1}$ ) is made in Fig. 7. This parity plot shows that the relation of Idogawa et al. [13] predicts gas hold-ups in water which are too high at the low gas velocities of 1 and $2 \mathrm{~cm}^{-1}$ respectively, but for gas velocities above $3 \mathrm{~cm} \mathrm{~s}^{-1}$ the agreement is satisfactory at all pressures. In contrast to these findings for water, we have found that the relation of Idogawa et al. [13] cannot be used to predict either the absolute gas hold-ups in the aqueous DEA solution or the dependence of the gas hold-up on either the pressure or the superficial gas velocity.

\subsubsection{Influence of pressure on the flow regimes}

Tarmy et al. $[5,6]$ also found a positive influence of the operating pressure on the gas hold-up. Furthermore, these authors observe that at higher pressures the transition from the bubbly flow towards the

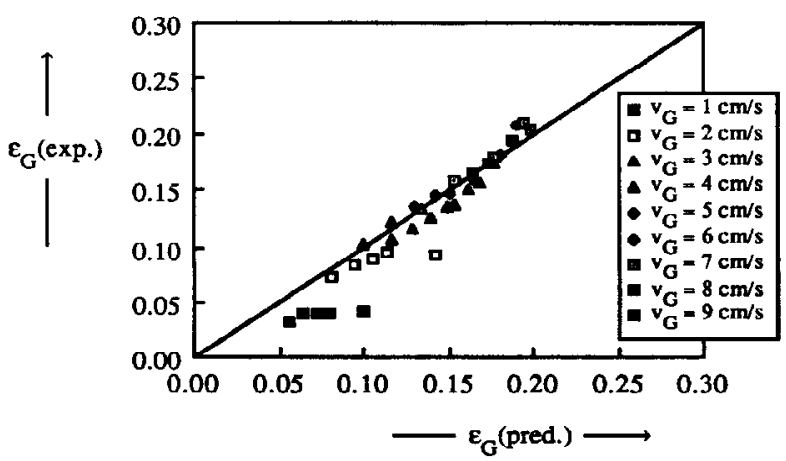

Fig. 7. Parity plot between the experimental gas hold-ups in water and those predicted by the correlation of Idogawa et al. [13]. 


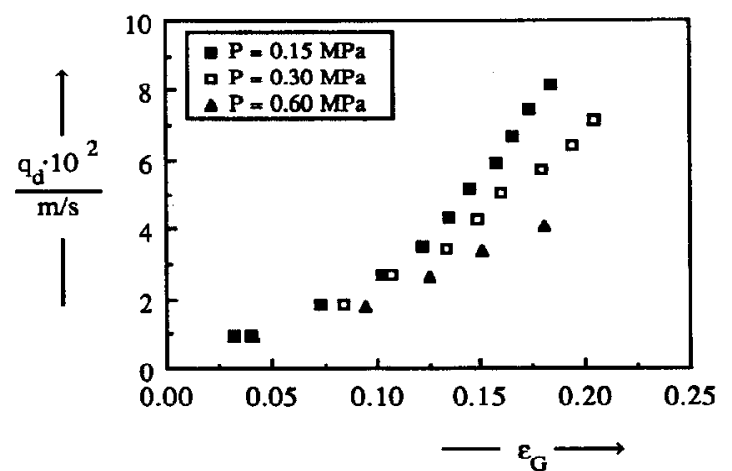

Fig. 8. Drift flux in water vs. the gas hold-up in the bubble column.

churn turbulent regime occurs at higher gas velocities and gas hold-ups. This transition in flow regime is normally evaluated in a plot of the drift flux $q_{d}$ versus the gas hold-up [23]. The drift flux $q_{\mathrm{d}}$ is defined as the volumetric gas flux relative to a surface moving at the average velocity of the dispersion. For a semi-batch system with a non-flowing liquid the drift flux is equal to

$q_{\mathrm{d}}=v_{\mathrm{G}}\left(1-\varepsilon_{\mathrm{G}}\right)$

Plots for the drift flux in water and in the aqueous DEA solution are presented in Figs. 8 and 9, respectively. At $0.15 \mathrm{MPa}$ the drift flux data in both liquids can be divided into two regions. In the first region, corresponding to the bubbly flow regime, the drift flux is relatively low and increases slowly with increasing gas hold-up. The second region corresponds to the churn turbulent regime where the drift flux is larger and increases rapidly with increasing gas holdup. In both liquids at a pressure of $0.15 \mathrm{MPa}$ the transition from the bubbly flow regime towards the churn tubulent regime occurs around $\varepsilon_{\mathrm{G}}=0.12-0.15$. This is in accordance with literature data on bubble columns with multi-nozzle gas distributors at atmospheric pressure [4].

It can also be seen in Figs. 8 and 9 that both the absolute values of $q_{\mathrm{d}}$ as well as the increase in $q_{\mathrm{d}}$ with

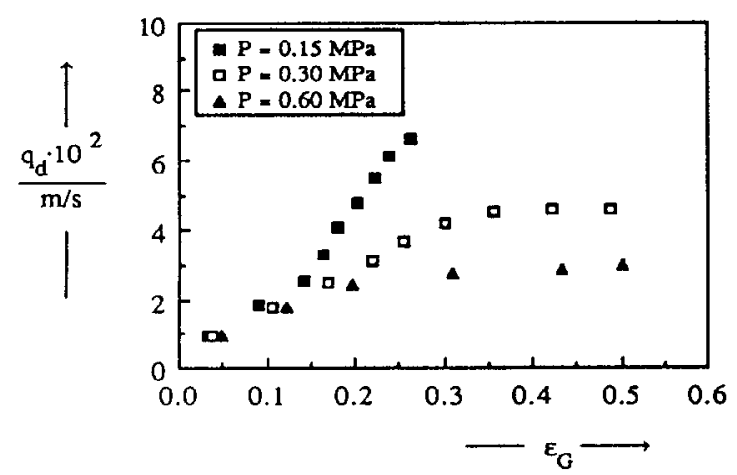

Fig. 9. Drift flux in a DEA solution partially loaded with $\mathrm{CO}_{2}$ vs. the gas hold-up in the bubble column.

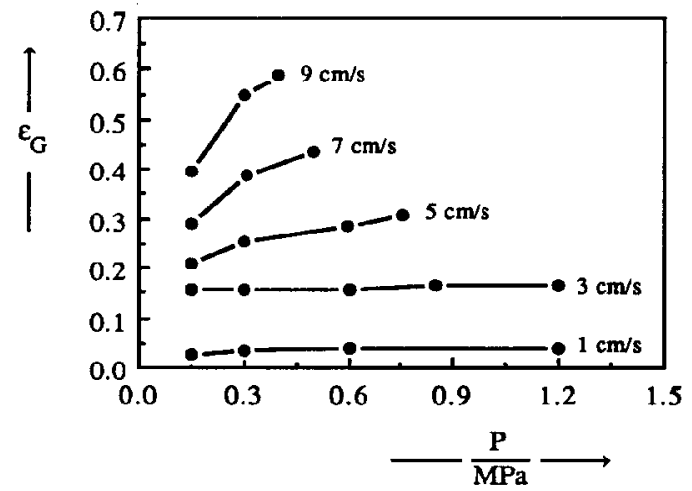

Fig. 10. Gas hold-up in water vs. the reactor pressure in the bubble column and with $H / D=3.2$.

$\varepsilon_{\mathrm{G}}$ are smaller at the higher pressures of 0.30 and $0.60 \mathrm{MPa}$. This indicates that at higher pressures the bubbly flow regime persists at higher gas hold-ups and gas velocities, which agrees with the findings of Tarmy et al. $[5,6]$.

The higher gas hold-ups at elevated pressures can be attributed to the initially smaller bubbles at the gas distributor, as concluded by Oyevaar and Westcrterp [7]. These smaller bubbles have lower rising velocities, which lead to higher gas hold-ups at constant superficial gas velocity. The persistence of the bubbly flow regime at these higher gas hold-ups also indicates that these smaller bubbles may be noncoalescing and therefore keep their identity throughout the whole column.

In a series of additional experiments we have determined gas hold-ups in water in the bubble column with a lower dispersion height of $27.0 \mathrm{~cm}$ $(H / D=3.2)$. The results of these measurements are presented in Fig. 10. A comparison with the gas hold-ups of Fig. 4 in water at $H / D=6.1$ shows that at $H / D=3.2$ the gas hold-ups are higher, except at $v_{\mathrm{G}}=1 \mathrm{~cm} \mathrm{~s}^{-1}$. This means that at higher gas velocities, and thus at higher gas hold-ups, the bubbles still coalesce in the upper part of the column. Also, the influence of the operating pressure on the gas hold-up is stronger at $H / D=3.2$, even for $v_{\mathrm{G}}=1 \mathrm{~cm} \mathrm{~s}^{-1}$. For an increase in the pressure from 0.15 to $0.30 \mathrm{MPa}$ the relative increase in the gas hold-up ranges from $20 \%$ at $v_{\mathrm{G}}=1 \mathrm{~cm} \mathrm{~s}^{-1}$ to $40 \%$ at $v_{\mathrm{G}}=9 \mathrm{~cm} \mathrm{~s}^{-1}$. These results are a strong indication that the positive influence of the operating pressure on the gas hold-up originates from the formation of smaller bubbles at the gas distributor. Both the increase in the gas hold-up and the decrease in the bubble diameters cause an increase in the interfacial area with pressure, as will be shown in the next section.

\subsection{Interfacial areas in the bubble column}

\subsubsection{Experimental results}

The operating pressures and the superficial gas velocities, which are applied in the absorption experiments for the determination of interfacial areas, are 


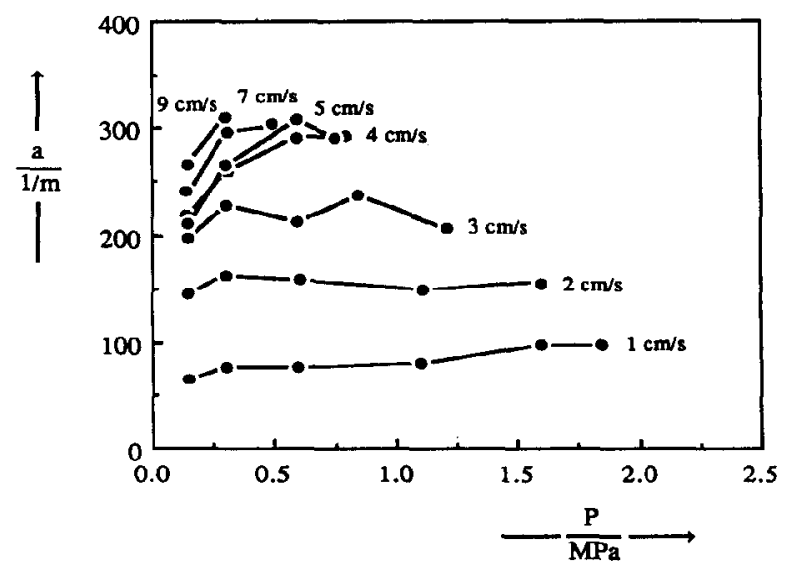

Fig. 11. Interfacial areas in a DEA solution partially loaded with $\mathrm{CO}_{2}$ vs. the reactor pressure in the bubble column.

TABLE 4. Interfacial areas and Sauter mean bubble diameters in the bubble column at different pressures $\left([D E A]=2.0-2.2 \mathrm{~mol} \mathrm{~kg}^{-1}\right)$

\begin{tabular}{|c|c|c|c|c|}
\hline $\begin{array}{l}v_{\mathrm{G}} \times 10^{2} \\
\left(\mathrm{~m} \mathrm{~s}^{-1}\right)\end{array}$ & $\begin{array}{l}P \\
(\mathrm{MPa})\end{array}$ & $\begin{array}{l}\zeta_{\mathrm{CO}_{2}} \\
(\%)\end{array}$ & $\begin{array}{l}a \\
\left(\mathrm{~m}^{-1}\right)\end{array}$ & $\begin{array}{l}d_{\mathrm{mb}} \times 10^{3} \\
(\mathrm{~m})\end{array}$ \\
\hline 1.0 & $\begin{array}{l}0.15 \\
0.30 \\
0.60 \\
1.10 \\
1.60 \\
1.85\end{array}$ & $\begin{array}{l}96 \\
97 \\
97 \\
98 \\
99 \\
99\end{array}$ & $\begin{array}{l}66 \\
77 \\
77 \\
80 \\
98 \\
97\end{array}$ & $\begin{array}{l}3.1 \\
3.0 \\
3.8 \\
3.7 \\
3.3 \\
3.5\end{array}$ \\
\hline 2.0 & $\begin{array}{l}0.15 \\
0.30 \\
0.60 \\
1.10 \\
1.60\end{array}$ & $\begin{array}{l}96 \\
98 \\
98 \\
97 \\
98\end{array}$ & $\begin{array}{l}147 \\
163 \\
158 \\
150 \\
156\end{array}$ & $\begin{array}{l}3.7 \\
3.9 \\
4.6 \\
5.6 \\
7.6\end{array}$ \\
\hline 3.0 & $\begin{array}{l}0.15 \\
0.30 \\
0.60 \\
0.85 \\
1.20\end{array}$ & $\begin{array}{l}95 \\
97 \\
96 \\
98 \\
96\end{array}$ & $\begin{array}{l}198 \\
228 \\
212 \\
238 \\
207\end{array}$ & $\begin{array}{l}4.3 \\
4.5 \\
5.6 \\
6.3 \\
8.8\end{array}$ \\
\hline 4.0 & $\begin{array}{l}0.15 \\
0.30 \\
0.60 \\
0.80\end{array}$ & $\begin{array}{l}93 \\
96 \\
97 \\
97\end{array}$ & $\begin{array}{l}221 \\
263 \\
294 \\
292\end{array}$ & $\begin{array}{l}4.5 \\
5.0 \\
6.3 \\
8.6\end{array}$ \\
\hline 5.0 & $\begin{array}{l}0.15 \\
0.30 \\
0.60 \\
0.75\end{array}$ & $\begin{array}{l}86 \\
92 \\
95 \\
94\end{array}$ & $\begin{array}{l}211 \\
266 \\
309 \\
291\end{array}$ & $\begin{array}{l}5.1 \\
5.7 \\
8.4 \\
9.8\end{array}$ \\
\hline 6.0 & $\begin{array}{l}0.15 \\
0.30 \\
0.60\end{array}$ & $\begin{array}{l}82 \\
89 \\
91\end{array}$ & $\begin{array}{l}217 \\
286 \\
296\end{array}$ & $\begin{array}{r}5.6 \\
6.3 \\
10.2\end{array}$ \\
\hline 7.0 & $\begin{array}{l}0.15 \\
0.30 \\
0.50\end{array}$ & $\begin{array}{l}80 \\
88 \\
87\end{array}$ & $\begin{array}{l}240 \\
314 \\
304\end{array}$ & $\begin{array}{r}5.5 \\
6.8 \\
10.9\end{array}$ \\
\hline 8.0 & $\begin{array}{l}0.15 \\
0.30\end{array}$ & $\begin{array}{l}79 \\
84\end{array}$ & $\begin{array}{l}263 \\
305\end{array}$ & $\begin{array}{l}5.5 \\
8.3\end{array}$ \\
\hline 9.0 & $\begin{array}{l}0.15 \\
0.30\end{array}$ & $\begin{array}{l}76 \\
81\end{array}$ & $\begin{array}{l}268 \\
312\end{array}$ & $\begin{array}{l}5.9 \\
9.4\end{array}$ \\
\hline
\end{tabular}

the same as in the gas hold-up experiments. The results are given in Table 4 and partially plotted in Fig. 11. It can be seen from this Figure that the interfacial areas are also influenced by the operating pressure and increase with increasing pressure for all the superficial gas velocities. The relative increase of the interfacial areas is largest for a pressure increase from 0.15 to $0.30 \mathrm{MPa}$ and varies between $10 \%$ and $30 \%$. At the higher superficial gas velocities it seems that the interfacial areas approach a maximum value at a pressure of $0.5 \mathrm{MPa}$.

The influence of pressure on the interfacial areas is smaller than on the gas hold-ups in an aqueous DEA solution of similar composition (compare Figs. 5 and 10 ). As the Sauter mean bubble diameter $d_{\mathrm{mb}}$ is related to the gas hold-up and the interfacial area according to

$d_{\mathrm{mb}}=6 \varepsilon_{G} / a$

this means that the bubble diameters increase with increasing pressure (see Table 4). However, such an increase in the bubble diameters with pressure has not been observed visually and is completely contrary to all the literature results up till now [7]. Besides, larger bubbles should also lead to lower gas hold-ups and interfacial areas, which is in contrast with the experimental results on $a$ and $\varepsilon_{\mathrm{G}}$. Therefore, we may ask ourselves whether either the experimental results on the gas hold-ups are too high or the absorption experiments result in an underestimation of the interfacial area.

\subsubsection{Underestimation of the interfacial area}

The use of eqn. (6) for the evaluation of interfacial areas from absorption experiments is in fact restricted to an ideally micromixed gas phase in plug flow. However, the gas phase in the bubble column is dispersed and subjected to finite coalescence and break-up rates. Moreover, the bubble sizes are not uniform. Schumpe and Deckwer [16] have shown that the gas-liquid dispersions with non-uniform bubble sizes the chemical method can lead to an underestimation of the interfacial area. This underestimation is a direct result of the use of an overall conversion for the reactant in the gas phase, while the conversion of the gas-phase reactant in a single bubble depends non-linearly on the specific area of the bubble. Besides that, the bubbles may have different residence times $\tau_{\mathrm{b}}$. These two phenomena lead to deviations of the chemically determined interfacial area $a_{\text {chem }}$ from the true geometric interfacial area $a_{\text {geo }}$. These deviations become larger the broader the distribution of $\tau_{\mathrm{b}} / d_{\mathrm{b}}$ and the higher the overall conversion of the reactant in the gas phase [16].

Oyevaar and Westerterp [24] modified the method of Schumpe and Deckwer [16] in order to calculate $a_{\text {chem }} / a_{\text {geo }}$ as a function of the overall conversion $\boldsymbol{\Omega}_{\mathrm{A}}$ of the gas-phase reactant and the bubble size distribution. Some calculated results for a bubble column and a first-order reaction with respect to the gasphase reactant, being the reaction between $\mathrm{CO}_{2}$ and 


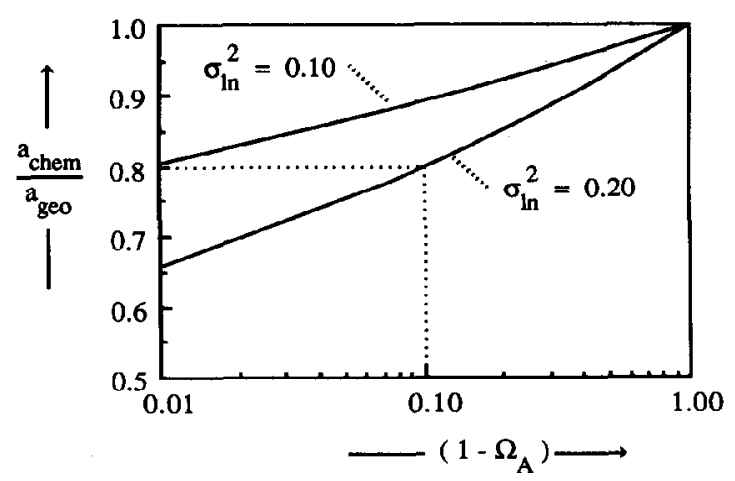

Fig. 12. Ratio $a_{\text {chem }} / a_{\text {geo }}$ for a log-normal distribution vs. $\mathbf{l}-\mathbf{\Omega}_{\mathrm{A}}$ for a first-order reaction and plug flow of the gas phase.

DEA in water, are given in Fig. 12. Bubble size distributions equal to a log-normal distribution with variances of $\sigma_{1 \mathrm{n}}{ }^{2}=0.10$ and 0.20 , found to be valid for a bubble column with single or multi-nozzle gas distributors by Akita and Yoshida [18], were used for the calculations. All bubbles are assumed to have the same residence time $\tau_{\mathrm{b}}$, to move separately, and to be completely segregated. Overall, the gas phase is assumed to be in plug flow. The geometric interfacial area $a_{\text {geo }}$ can be obtained from the Sauter mean bubble diameter, whereas the chemically determined interfacial area $a_{\text {chem }}$ is evaluated from the overall conversion $\Omega_{\mathrm{A}}$ obtained by a summation of the conversions per class of bubble diameters [24].

It can be seen in Fig. 12 that $a_{\text {chem }} / a_{\text {geo }}$ decreases with increasing overall conversions $\Omega_{\mathrm{A}}$ and variances $\sigma_{\mathrm{ln}}{ }^{2}$. The error in $a_{\text {chem }}$ becomes larger than $20 \%$ for overall conversions $\Omega_{\mathrm{A}}$ larger than 0.90 and amounts to about $35 \%$ at $\Omega_{\mathrm{A}}=0.99$ and $\sigma_{\ln }{ }^{2}=0.20$. However, Oyevaar and Westerterp [24] also report that, if realistic coalescence and break-up rates between the bubbles are taken into account, the error in $a_{\text {chem }}$ will decrease considerably and become less than $20 \%$ for overall conversions $\Omega_{\mathrm{A}}$ lower than 0.99 (also see Fig. 12). Therefore, it can be concluded that the use of eqn. (6) for the evaluation of interfacial areas is justified and does not lead to the large underestimations of the interfacial area which could account for the increase of the Sauter mean bubble diameter with pressure, as shown in Table 4.

Because the absorption rate constants $m\left[k_{1, p}\left(C_{\mathrm{DEA}, \mathrm{L}}\right)^{p} D_{\mathrm{CO}_{2}}\right]^{0.5}$ are also known to within an experimental accuracy of $5 \%$, this means that part of the experimentally determined gas hold-ups does not contribute to the mass transfer of $\mathrm{CO}_{2}$. This is probably caused by the following two phenomena, which have been observed visually in the aqueous DEA solutions at atmospheric and at elevated pressures:

(1) the formation of a froth layer in the upper part of the dispersion-this froth layer is more pronounced at higher superficial gas velocities and is less effective in the mass transfer of $\mathrm{CO}_{2}$;

(2) the occurrence of tiny bubbles with diameters smaller than $1 \mathrm{~mm}$ and with long residence timesthese tiny bubbles accumulate in the dispersion and are in equilibrium with the liquid phase; they do not contribute to the mass transfer of $\mathrm{CO}_{2}$.

These two phenomena have also been observed in aqueous glycol mixtures by Bach and Pilhofer [25] and in organic liquid mixtures by Öztürk et al. [22]. The tiny bubbles originate from the gas distributor and are more pronounced at high kinetic energy contents of the gas phase, and thus at higher pressures and at higher gas velocities [11]. These findings indicate that part of the dispersed gas phase does not contribute or contributes less to the mass transfer of $\mathrm{CO}_{2}$. However, unfortunately it is not possible to determine the hold-up of these tiny bubbles within the experimental bubble column separately from the other bubbles.

\subsubsection{Comparison with literature correlations}

A comparison between the interfacial areas at $0.15 \mathrm{MPa}$ from this study and those calculated with the correlation of Akita and Yoshida [18] (see Table 3 ) is presented in Fig. 13. It can be seen that the interfacial areas predicted by the relation of Akita and Yoshida [18] are around a factor of 2 lower than the experimental values of this study. It is known that this relation results in a conservative value for the interfacial areas [4]. A much better agreement can be obtained with literature data on interfacial areas in sulphite solutions in bubble columns reported by Schumpe and Deckwerts $[16,26]$. These authors summarize data on interfacial areas which have been presented by several investigators for different bubble columns over a wide range of operating conditions. The comparison between these literature data and the interfacial areas in aqueous DEA of $0.15 \mathrm{MPa}$ is good. Therefore, it can be concluded that the interfacial areas at atmospheric pressures determined by us are realistic.

The line representing the interfacial areas at $0.15 \mathrm{MPa}$, calculated from the relations of Idogawa et al. [13] for the gas hold-up (see eqn. (12)) and for

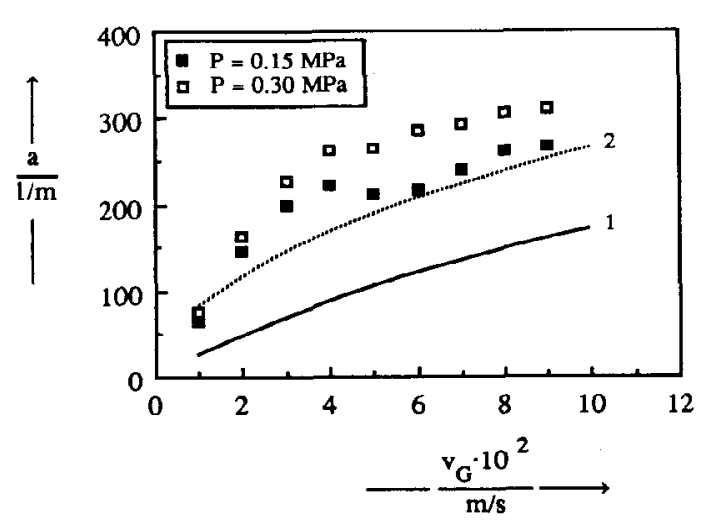

Fig. 13. Comparison between literature correlations for interfacial areas and the data of the present study: curve 1, Akita and Yoshida [18]; curve 2, Idogawa et al. [13]. 
the Sauter mean bubble diameter

$d_{\mathrm{mb}}=3.10 \times 10^{-3} \rho_{\mathrm{L}}{ }^{-0.028} \sigma_{\mathrm{L}}^{0.088 \exp (-P)}$

(in SI units, except for $P$ in $\mathrm{MPa}$ and $\sigma_{\mathrm{L}}$ in $\mathrm{mN} \mathrm{m}^{-1}$ ), is also plotted in Fig. 13. In contrast to the relation of Akita and Yoshida [18] it can be seen that the interfacial areas according to the relations of Idogawa et al. [13] compare rather well with the experimental data for the interfacial areas at $0.15 \mathrm{MPa}$. A parity plot between the interfacial areas at all pressures and those predicted by the correlations of Idogawa et al. [13] is presented in Fig. 14. The parity plot shows that the literature relations of Idogawa et al. [13] predict interfacial areas which are too high for the lower superficial gas velocities at the higher operating pressures. Moreover, our interfacial areas are more or less independent of pressure for the lower superficial gas velocities, whereas Idogawa et al. [13] do predict a strong pressure influence. However, the agreement at superficial gas velocities higher than $3 \mathrm{~cm} \mathrm{~s}^{-1}$ is satisfactory for all experimental conditions.

It can be seen in Fig. 13 that the interfacial areas at $0.15 \mathrm{MPa}$ increase with an increasing superficial gas velocity up to $4 \mathrm{~cm} \mathrm{~s}^{-1}$, then remain constant around a value of $220 \mathrm{~m}^{-1}$ for superficial gas velocities up to $6 \mathrm{~cm} \mathrm{~s}^{-1}$ and start to increase again for higher gas velocities. This has already been observed for the interfacial areas obtained from the Danckwerts plots (see Table 2). The plateau value of the interfacial areas as a function of the superficial gas velocity is caused by the transition from the bubbly flow towards the churn turbulent regime around superficial gas velocities of $5 \mathrm{~cm} \mathrm{~s}^{-1}$ [4]. Schumpe et al. [27] demonstrated experimentally that the transition in flow regimes is accompanied by a sharp decrease in the conversion of the gas-phase reactant. This effect can also be observed for the $\mathrm{CO}_{2}$ conversions at $0.15 \mathrm{MPa}$ in Table 4 .

The results for the gas hold-ups in both water and in aqueous DEA solution at elevated pressures reveal that the transition from the bubbly flow towards the churn turbulent regime is influenced by the operating

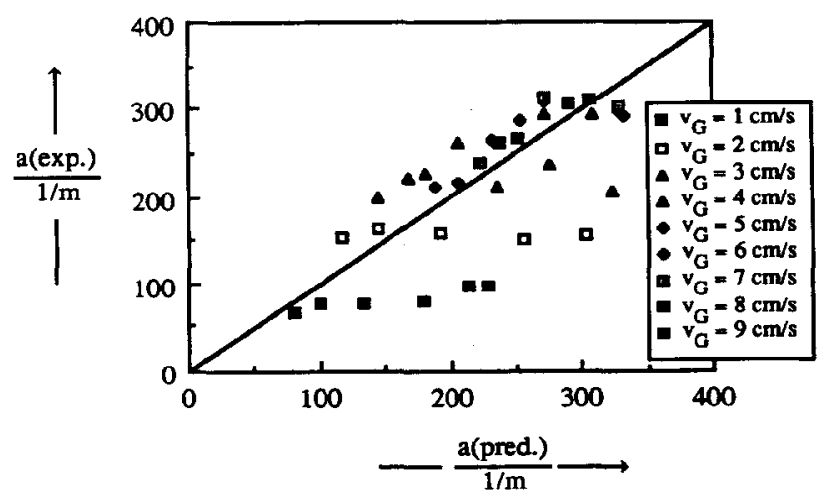

Fig. 14. Parity plot between the experimental interfacial area and those predicted by the correlations of Idogawa et al. [13]. pressure. The interfacial areas at a pressure of $0.30 \mathrm{MPa}$ are therefore also plotted in Fig. 13 in order to verify whether this can also be concluded from the results on the interfacial areas. As can be seen in Fig. 13 the plateau has almost disappeared at a pressure of $0.30 \mathrm{MPa}$ and indeed the transition between the two flow regimes is influenced by the operating pressure.

\subsection{Interfacial areas in the packed bubble column}

In addition to the experiments in the two-phase bubble column we have determined gas hold-ups and interfacial areas in a three-phase bubble column. We filled the column with glass cylinders with a length and diameter equal to 5.0 and $4.0 \mathrm{~mm}$ respectively. This results in a packed bubble column with similar geometry to that used by van Gelder and Westerterp [2] for the determination of the liquid-phase residence time distribution and hold-ups at elevated pressures.

Packed bubble columns are used, for example, in hydrogenation and oxidation processes for which long liquid-phase residence times and low liquidphase backmixing are required. Literature data on the hydrodynamics and mass transfer characteristics in packed bubble columns are scarce and are often obtained for larger columns with larger and other types of packing and for higher gas and liquid flows than applied in this study. Besides the aforementioned article of van Gelder and Westerterp [2], no information for packed bubble columns at elevated pressures seems to be available; these authors concluded that at constant volumetric gas flow rates, the hold-ups in a packed bubble column are unaffected by the operating pressure.

\subsubsection{Liquid-phase mass transfer coefficients}

Liquid-phase mass transfer coefficients $k_{\mathrm{L}}$ in the packed bubble column were determined by means of the Danckwerts plot method in a series of absorption experiments at $0.15 \mathrm{MPa}$ and at the four different superficial gas velocities of $0.5,1.0,2.0$ and $3.0 \mathrm{~cm} \mathrm{~s}^{-1}$. These superficial gas velocities are based on the empty cross-sectional area of the column and correspond to gas velocities, based on the empty cross-sectional area of the packed column, equal to $1.4,2.9,5.7$ and $8.6 \mathrm{~cm} \mathrm{~s}^{-1}$ respectively. In order to compare the performance of the packed bubble column with that of the bubble column, all results on interfacial area and gas hold-ups reported for the packed bubble column will be corrected for the bed porosity and based on the true volume available for gas and liquid.

The absorption experiments were performed in five different aqueous DEA solutions with DEA concentrations between 0.10 and $0.85 \mathrm{~mol} \mathrm{~kg} \mathrm{~kg}^{-1}$. The Danckwerts plots obtained from these experiments are shown in Fig. 15 and the values for $k_{\mathrm{L}}$ and $a$ so obtained are given in Table 5: it can be seen that $k_{\mathrm{L}}$ remains practically constant and has an average value of $2.6 \times 10^{-4} \mathrm{~m} \mathrm{~s}^{-1}$. This value agrees very 


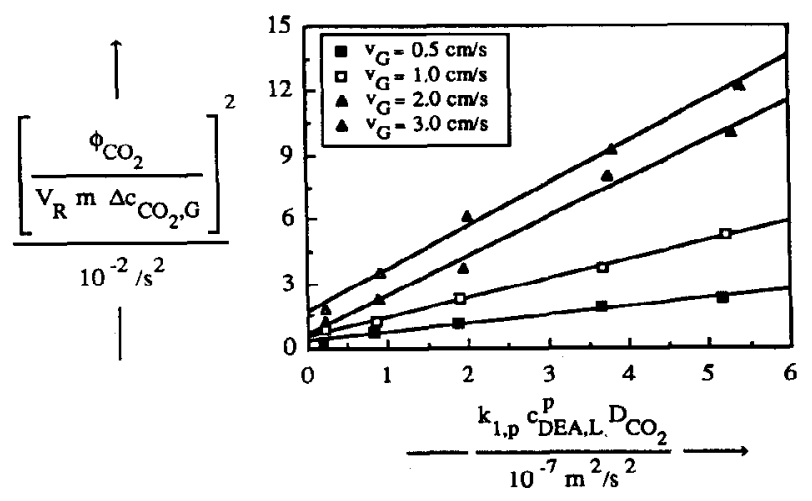

Fig. 15. Danckwerts plots for the packed bubble column at a pressure of $0.15 \mathrm{MPa}$.

well with the value of $2.5 \times 10^{-4} \mathrm{~m} \mathrm{~s}^{-1}$ obtained for $k_{\mathrm{L}}$ by Pexidr and Charpentier [28] in a bubble column packed with $6.4 \mathrm{~mm}$ Raschig rings and with a column height and diameter of $1.75 \mathrm{~m}$ and $0.10 \mathrm{~m}$ respectively. From eqns. (7) and (8) it can be calculated that with $k_{\mathrm{L}}=2.5 \times 10^{-4} \mathrm{~m} \mathrm{~s}^{-1}$ a free DEA concentration of $1.2 \mathrm{~mol} \mathrm{~kg}^{-1}$ results in $\mathrm{Ha}=4.0$. Together with a maximum DEA conversion of $20 \%$ this leads to a recommended total DEA concentration of $1.5 \mathrm{~mol} \mathrm{~kg}^{-1}$ in the amine solutions for the determination of interfacial areas.

\subsubsection{Interfacial areas}

Absorption experiments in the packed bubble column were performed for pressures between 0.25 and $1.30 \mathrm{MPa}$ and at superficial gas velocities of 1.0 , 2.0 and $3.0 \mathrm{~cm} \mathrm{~s}^{-1}$. All experimental results are given in Table 6 and plotted in Fig. 16: it is evident that the interfacial areas in the packed bubble column are not influenced by pressure up to operating pressures of $1.3 \mathrm{MPa}$. This is in agreement with the independence of the gas hold-ups on pressure in a packed bubble column reported by van Gelder and Westerterp [2].

Under the same operating conditions, all interfacial areas in the packed bubble column are much higher than those in the bubble column (presented in Table 4). A comparison between the interfacial areas in the two bubble columns on the basis of the reactor volume of the column is shown in Fig. 17: it can be seen that at the lowest superficial gas velocity of $1.0 \mathrm{~cm} \mathrm{~s}^{-1}$ the interfacial areas in the packed bubble

TABLE 5. Results of the Danckwerts plots for the packed bubble column at a pressure of $0.15 \mathrm{MPa}\left([\mathrm{DEA}]=0.10-0.85 \mathrm{~mol} \mathrm{~kg} \mathrm{~kg}^{-1}\right)$

\begin{tabular}{lll}
\hline $\begin{array}{l}v_{\mathrm{G}} \times 10^{2} \\
\left(\mathrm{~m} \mathrm{~s}^{-1}\right)\end{array}$ & $\begin{array}{l}k_{\mathrm{L}} \times 10^{4} \\
\left(\mathrm{~m} \mathrm{~s}^{-1}\right)\end{array}$ & $\begin{array}{l}a \\
\left(\mathrm{~m}^{-1}\right)\end{array}$ \\
\hline 0.5 & 2.98 & 200 \\
1.0 & 2.49 & 297 \\
2.0 & 2.07 & 423 \\
3.0 & 2.94 & 443 \\
\hline
\end{tabular}

TABLE 6. Interfacial areas in the packed bubble column at different pressures $\left([D E A]=1.5 \mathrm{~mol} \mathrm{~kg}^{-1}\right.$ )

\begin{tabular}{llll}
\hline $\begin{array}{l}v_{\mathrm{G}} \times 10^{2} \\
\left(\mathrm{~m} \mathrm{~s}^{-1}\right)\end{array}$ & $\begin{array}{l}P \\
(\mathrm{MPa})\end{array}$ & $\begin{array}{l}\zeta_{\mathrm{CO}} \\
(\%)\end{array}$ & $\begin{array}{l}a \\
\left(\mathrm{~m}^{-1}\right)\end{array}$ \\
\hline 1.0 & 0.25 & 99 & 340 \\
& 0.40 & 99 & 340 \\
& 0.70 & 98 & 271 \\
& 1.00 & 98 & 274 \\
& 1.30 & 99 & 306 \\
2.0 & & & \\
& 0.25 & 95 & 431 \\
& 0.40 & 95 & 449 \\
& 0.70 & 95 & 426 \\
& 1.00 & 95 & 423 \\
3.0 & 1.30 & 94 & 423 \\
& & & \\
& 0.25 & 90 & 517 \\
& 0.40 & 92 & 551 \\
& 0.70 & 91 & 526 \\
& 1.00 & 90 & 506 \\
& 1.30 & 91 & 506 \\
\hline
\end{tabular}

column are still higher. However, for the superficial gas velocity of $3.0 \mathrm{~cm} \mathrm{~s}^{-1}$ the interfacial areas in the packed bubble column, as based on the total volume of the column, become smaller than those in the bubblc column.

The higher interfacial areas at $1.0 \mathrm{~cm} \mathrm{~s}^{-1}$ can be attributed to lower rising velocities of the bubbles in the packed column and to the fact that larger bubbles are broken on the edges of the packing material $[28,29]$. It has also been observed that the bubbles tend to form chains throughout the packed column. These chains of bubbles lead to a smaller increase of the interfacial area in the packed bubble column with increasing gas velocity as compared with interfacial areas in the bubble column.

Results on interfacial areas obtained by the chemical method at high conversions of the gas-phase reactant should be considered carefully. As the conversions of $\mathrm{CO}_{2}$ become larger than $80 \%$ the evaluation of interfacial areas becomes sensitive to the assumed residence time distribution of the gas

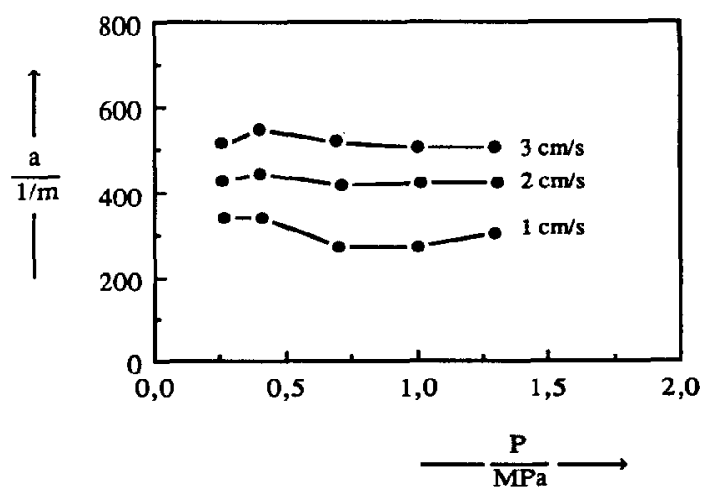

Fig. 16. Interfacial areas in a DEA solution partially loaded with $\mathrm{CO}_{2}$ vs. the reactor pressure in the packed bubble column. 


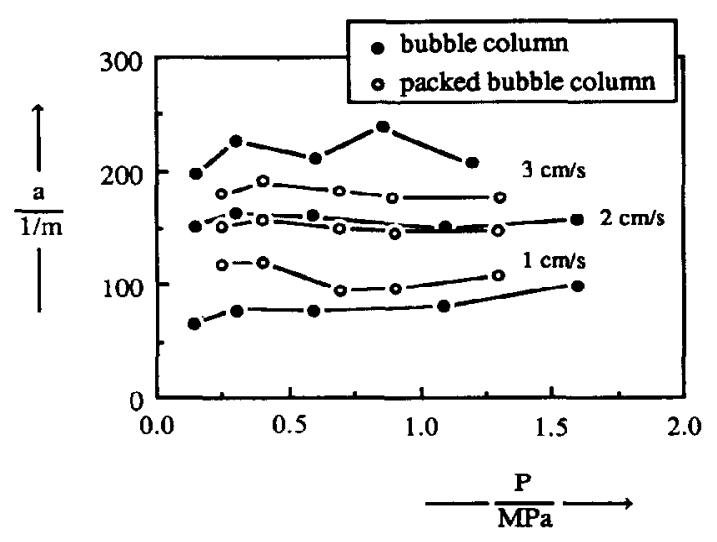

Fig. 17. Comparison between the interfacial areas based on the reactor volume in the bubble column and in the packed bubble column.

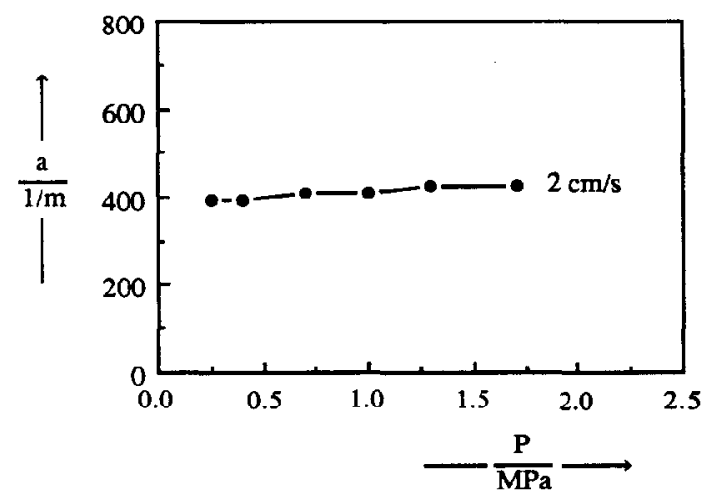

Fig. 18. Interfacial areas in a DEA solution partially loaded with $\mathrm{CO}_{2}$ vs. the reactor pressure in the packed bubble column and with $H / D=3.2$

phase [1]. Therefore, we also performed absorption experiments in a shorter packed column with a packing height of $27.0 \mathrm{~cm}(H / D=3.2)$. This lower height results in $\mathrm{CO}_{2}$ conversion levels around $70 \%$. The interfacial areas at a superficial gas velocity of $2.0 \mathrm{~cm} \mathrm{~s}^{-1}$ are plotted in Fig. 18: the values are equal to those at $2.0 \mathrm{~cm} \mathrm{~s}^{-1}$ in the packed bubble column with a packing height at $H / D=6.2$. This indicates that the interfacial areas determined in the packed bubble column with a packing height at $H / D=6.2$ are realistic and that the assumed plug flow behaviour for the gas phase is correct.

\section{Discussion and conclusions}

The results from this study show that the gas hold-ups in the bubble column increase with increasing pressure. The positive influence of the operating pressure on the gas hold-ups in water is qualitatively in agreement with the literature results reported for water and organic liquids in bubble columns at elevated pressures $[5,6,12,21]$. The gas hold-ups in water can be predicted fairly well with the correlation of Idogawa et al. [13]. For an aqueous DEA solution the increase in gas hold-up with pressure is even larger than for water. However, interfacial area determinations indicate that part of the gas hold-up in this DEA solution consists of a layer of froth, which is less effective for mass transfer.

Plots of the drift flux $q_{\mathrm{d}}$ versus the gas hold-ups in the bubble column at elevated pressures indicate that the transition from the bubbly flow to the churn turbulent regime occurs at higher gas velocities and higher gas hold-ups. These findings are in agreement with the results of Tarmy $e t a l$. $[5,6]$. It offers the interesting possibility of operating a bubble column at elevated pressures in the bubbly flow regime at higher volumetric gas throughputs than attainable in a column operating at atmospheric pressure. Operation of a bubble column in the bubbly flow regime may be required for high gas-phase conversions, but may also be preferred, if low liquid-phase backmixing is required, for selectivity. So, if selectivity is an important design objective, the liquid-phase residence time distribution at higher pressures should be investigated in the development of a gas-liquid process in a bubble column operating at elevated pressures.

Interfacial areas in the bubble column determined by the chemical method in an aqueous DEA solution also cxhibit an incrcase with increasing pressure. However, this increase is smaller than the increase in the gas hold-ups for the same solution. Comparison shows that the relative increase of the interfacial area in the aqueous DEA solutions with pressure is more in line with the relative increase of the gas hold-ups in water for the same range of operating pressures.

As no information is available in the literature on interfacial areas in bubble columns at higher pressures, no direct comparison is possible. The correlations of Idogawa et al. [13] on gas hold-ups and Sauter mean bubble diameters in bubble columns at elevated pressures can be used for a calculation of interfacial area. Although the gas hold-ups, as calculated from these relations, do not agree with the experimental gas hold-ups in the aqueous DEA solution, the calculated interfacial areas agree fairly well with the experimental interfacial area. However, in order to answer the question whether the relations of Idogawa et al. [13] can be used to predict the influence of pressure on gas hold-up and interfacial area in a bubble column, further research over a wider range of operating conditions and column geometries should be conducted.

Oyevaar and Westerterp [7] conclude that the initial bubble size at a single orifice decreases with increasing pressure. Gas hold-up measurements in the bubble column with a dispersion level at half of the original height indicate that the positive influence of pressure on the gas hold-up originates from the formation of smaller bubbles at the gas distributor. These smaller bubbles have lower rising velocities 
and lead to an increase in the gas hold-up and interfacial area with increasing pressures.

Comparison of the gas hold-ups and the interfacial areas in the bubble and the packed bubble column of this study and the same results for a mechanically agitated reactor at elevated pressures [1] confirms that the pressure influence originates from the formation of smaller bubbles at the gas distributor. Both the mechanically agitated reactor and the packed bubble column exhibit no influence of pressure on the gas hold-ups and interfacial areas, because in both gas-liquid contactors the coalescence-break-up process of the bubbles is dominated by the agitator or the packing. Any influence of pressure on the bubble formation at the gas distributor is therefore masked by the coalescence-break-up process in these contactors.

In a bubble column the gas hold-up and interfacial areas are partly dependent on the bubble formation process at the gas distributor and therefore this contactor exhibits a positive pressure effect. The effect of pressure may also be masked in long bubble columns in which the gas hold-ups and interfacial areas are mainly determined by the coalescence-break-up equilibrium in the column.

\section{Acknowledgements}

The investigations were supported by the Netherlands Foundation for Chemical Research (SON) with financial aid from the Netherlands Organization for the Advancement of Scientific Research (NWO).

\section{Nomenclature}

a specific interfacial area, $\mathrm{m}^{2} / \mathrm{m}^{3}$ dispersion

c concentration, $\mathrm{mol} \mathrm{m}^{-3}$

$\Delta c \quad$ driving force for mass transfer, $\mathrm{mol} \mathrm{m}^{-3}$

$D$ vessel diameter, $m$

$D_{\mathrm{A}}$ diffusivity of component $\mathrm{A}$ in liquid phase, $\mathrm{m}^{2} \mathrm{~s}^{-1}$

$D_{\mathrm{B}}$ diffusivity of component $\mathrm{B}$ in liquid phase, $\mathrm{m}^{2} \mathrm{~s}^{-1}$

$d_{\mathrm{b}} \quad$ bubble diameter, $\mathrm{m}$

$d_{\mathrm{mb}} \quad$ Sauter mean bubble diameter, $\mathrm{m}$

$E_{\mathrm{A}} \quad$ enhancement factor, eqn. (1)

$E_{\mathrm{A}, \infty}$ enhancement factor for infinitely fast reaction, eqn. (4)

$g$ gravitational acceleration, $\mathrm{m} \mathrm{s}^{-2}$

$H$ dispersion height, $\mathrm{m}$

$\mathrm{Ha}$ Hatta number, eqn. (3)

$h \quad$ gas distributor height, $\mathrm{m}$

$I \quad$ ionic strength, $\mathrm{kg}$ ion $/ \mathrm{m}^{3}$

$k_{\mathbf{L}} \quad$ liquid-phase mass transfer coefficient, $\mathrm{m} \mathrm{s}^{-1}$

$k_{n, p} \quad$ reaction rate constant for reaction of order $(n, p), \mathrm{m}^{3(p+n-1)} / \mathrm{mol}^{(p+n-1)} \mathrm{s}$

$m$ distribution coefficient, $c_{\mathrm{L}}=m c_{\mathrm{G}}$

$p \quad$ pressure, $\mathrm{Pa}$

$q_{\mathrm{d}} \quad$ drift flux, $\mathrm{m} \mathrm{s}^{-1}$

$q_{\mathrm{d}} \quad$ volume, $\mathrm{m}^{3}$ $v$ superficial velocity based on empty cross-sectional area of vessel, $\mathrm{m} \mathrm{s}^{-1}$

$\varepsilon \quad$ hold-up

$\zeta \quad$ conversion

$\mu$ dynamic viscosity, $\mathrm{N} \mathrm{s} \mathrm{m}^{-2}$

$v \quad$ kinematic viscosity, $\mathrm{m}^{2} \mathrm{~s}^{-1}$

$v_{B} \quad$ stoichiometric coefficient of component B $\left(v_{\mathrm{A}}=1\right)$

$\rho$ density, $\mathrm{kg} \mathrm{m}^{-3}$

$\sigma$ surface tension, $\mathrm{N} \mathrm{m}^{-1}$

$\sigma_{\ln }^{2} \quad$ variance of log-normal distribution

$\tau_{\mathrm{b}} \quad$ bubble residence time, $\mathrm{s}$

$\phi \quad$ flow rate, $\mathrm{m}^{3} \mathrm{~s}^{-1}$ or $\mathrm{mol} \mathrm{s}^{-1}$

$\boldsymbol{\Omega}$ overall conversion

\section{Indices}

A component originally in gas phase

B component originally in liquid phase

b bubble

chem chemical

free free amine

G gas

geo geometric

in inlet

L liquid

$n \quad$ reaction rate order for component $\mathrm{A}$ in liquid phase

out outlet

$p \quad$ reaction rate order for component $B$ in liquid phase

R reactor

$\mathrm{V}$ volumetric

\section{References}

1 M. H. Oyevaar, A. D. Zijl and K. R. Westerterp, Interfacial areas and gas hold-ups at elevated pressures in a mechanically agitated gas-liquid reactor, Chem. Eng. Technol, II (1988) $1-10$.

2 K. B. van Gelder and K. R. Westerterp, Residence time distribution and hold-up in a cocurrent upflow packed bed reactor at elevated pressures and low Reynolds numbers, Chem. Eng. Technol., in press.

$3 \mathrm{H}$. Van Landeghem, Multiphase reactors: mass transfer and modelling, Chem. Eng. Sci., 35 (1980) 1912-1949.

4 Y. T. Shah, B. G. Kelkar, S. R. Godbole and W.-D. Deckwer, Design parameter estimations for bubble column reactors, AIChE J., 28 (1982) 353-379.

5 B. L. Tarmy, M. Chan, C. A. Coulaloglou and P. R. Ponzi, Hydrodynamic characteristics of three phase reactors, Chem. Eng., (Oct.) (1984) 18-23.

6 B. L. Tarmy, M. Chan, C. A. Coulaloglou and P. R. Ponzi, The three phase hydrodynamic characteristics of the EDS coal liquefaction reactors; their development and scaleup, Inst. Chem. Eng. Symp. Ser., No. 87, (1984) 303-317.

$7 \mathrm{M}$. H. Oyevaar and K. R. Westerterp, Mass transfer phenomena and hydrodynamics in agitated gas-liquid reactors and bubble columns at elevated pressures: state of the art, Chem. Eng. Process., 25 (1989) $85-98$.

8 G. Kling, UUber die Dynamik der Blasenbildung beim Begasen von Flüssigkeiten unter Druck, Int. J. Heat Mass Transfer, 5 (1962) $211-223$. 
9 R. D. LaNauze and I. J. Harris, Gas bubble formation at elevated pressures, Trans. Inst. Chem. Eng., 52 (1974) 337-348.

$10 \mathrm{~N}$. H. Sagert and M. J. Quinn, The coalescence of $\mathrm{H}_{2} \mathrm{~S}$ and $\mathrm{CO}_{2}$ bubbles in water, Can. J. Chem. Eng., 54 (1976) $392-398$.

11 K. Idogawa, K. Ikeda, T. Fukuda and S. Morooka, Formation and flow of gas bubbles in a pressurized bubble column with a single orifice or nozzle gas distributor, Chem. Eng. Commun., 59 (1987) 201-212.

12 A. Teurlings, D. Thoenes and L. L. van Dierendonck, Personal communication, Eindhoven Univ., 1986.

13 K. Idogawa, K. Ikeda, T. Fukuda and S. Morooka, Effect of gas and liquid properties on the behavior of bubbles in a column under high pressure, Int. Chem. Eng., 27 (1987) 93- 99.

14 P. V. Danckwerts, Gas-Liquid Reactions, McGraw-Hill, London, 1970.

15 A. Schumpe, A. K. Saxena and L. K. Fang, Gas/liquid mass transfer in a slurry bubble column, Chem. Eng. Sci., 42 (1987) 1787-1797.

16 A. Schumpc and W.-D. Deckwer, Analysis of chemical methods for determination of interfacial areas in gas-liquid dispersions with non-uniform bubble sizes, Chem. Eng. Sci., 35 (1980) 2221-2233.

17 P. H. Calderbank and M. B. Moo-Young, The continuous phase heat and mass transfer properties of dispersions, Chem. Eny. Sci., 16 (1961) 39-54.

$18 \mathrm{~K}$. Akita and F. Yoshida, Bubble size, interfacial area and liquid phase mass transfer coefficients in bubble columns, Ind. Eng. Chem., Process Des. Dev., 13 (1974) 84-91.
19 K. Akita and F. Yoshida, Gas hold-up and volumetric mass transfer coefficient in bubble columns, Ind. Eng. Chem., Process Des. Dev., 12 (1973) 76-80.

20 H. Hikita, S. Asai, K. Tanigawa, K. Segawa and M. Kitao, Gas hold-up in bubble columns, Chem. Eng. J., 20 (1980) $59-67$.

21 N. J. M. Pijls, D. Thoenes and L. L. van Dierendonck, Personal communication, Eindhoven Univ., 1985.

22 S. S. Oztürk, A. Schumpe and W.-D. Deckwer, Organic liquids in a bubble column: hold-ups and mass transfer coefficients, AIChE J., 33 (1987) 1473-1480.

23 G. B. Wallis, One-Dimensional Two-Phase Flow, McGraw-Hill, New York, 1969.

24 M. H. Oyevaar and K. R. Westerterp, The use of the chemical method for the determination of interfacial areas in gas-liquid contactors, Chem. Eng. Sci., in press.

25 F. B. Bach and T. Pilhofer, Variation of gas hold-up in bubble columns with physical properties of liquids and operating parameters of columns, Ger. Chem. Eng., 1 (1978) 270-275.

26 A. Schumpe and W.-D. Deckwer, Comparison of the photographic and the sulfite oxidation method for interfacial area determination in bubble columns, Chem. Eng. Commun., 17 (1982) 313-324.

27 A. Schumpe, Y. Serpemen and W.-D. Deckwer, Effective use of bubble columu reactors, Ger. Chem. Eny., 2 (1979) 234.

28 V. Pexidr and J.-C. Charpentier, The hydrodynamics and mass transfer in a packed bed bubble column, Coll. Czech. Chem. Commun., 40 (1975) 3130-3144.

29 W. Böxkes and H. Hofmann, Hydrodynamik und Stoffaustausch in gepackten Blasensäulen, Vt-Verfahrenstechnik, 9 (1975) 112-117. 